\title{
[ARTICLE]
}

\section{ON THE DEVELOPMENT OF THE POINT IS AND RELATED ISSUES IN THE HISTORY OF AMERICAN ENGLISH}

\author{
REIJIROU SHIBASAKI \\ Meiji University
}

\begin{abstract}
This study pays attention to the fairly recent development of the construction the point is especially from Late Modern through Present-Day periods in the history of American English. The main clause type (i.e. the point is that ...) and the DM type (i.e. the point is, ...) have been in rivalry since the mid-nineteenth century when they emerged, though the latter became dominant in the 2000s. The whole grammaticalization process of the point $i s$ rendered a variety of meso- and micro-constructions, however, not all of which have equally been entrenched: the determiner-modified the point is construction is no doubt a highly frequent construction, while the development of the first person singular possessive construction, i.e., my point is, can be considered a reflection of syntactic subjectivity.*
\end{abstract}

Keywords: discourse marker, parenthetical, construction, grammaticalization

\section{Introduction}

Discourse markers (DMs, hereafter) have been well explored at each sychronic stage in the history of English (e.g. Brinton (1996, 2008)). While DMs constitute no rigid grammatical class, they bear some affinity to other categories such as interjections in terms of some syntactic and semanticopragmatic properties, i.e., they are syntactically independent, semantically

* This study is part of my Grant-in-Aid for Young Scientists (B) research project (No. 22720194) supported by Japan Society for the Promotion of Science and part of Grant-inAid for Scientific Research (C) (No. 25370569) supported by The Ministry of Education, Culture, Sports and Technology, Japan. The earlier versions of the paper were presented at The Seventeenth International Conference of English Historical Linguistics (ICEHL-17), Zürich, Switzerland, Aug. 20-25, 2012, and at The Foreign Language and Literature Society of Okinawa 28, July 6, 2013. Thanks go to Anne Curzan, Teresa Fanego, Izumi Nishi and two anonymous $E L$ reviewers for their invaluable comments and constructive criticism and to Karin Aijmer, Joan C. Beal and Wolfgang Imo for their providing relevant information to me. Any remaining faults are all my own. 
non-referential or non-propositional, pragmatically textual and interpersonal (Brinton (2010)). DMs have been labled in a variety of ways, e.g. "parenthetical" (e.g. Huddleston and Pullum (2002)), "comment clause" (Quirk et al. (1985)), "epistemic phrase" (Wierzbicka (2006)), etc. Many preceding studies tell us that DMs have their own histories. Some DMs have been preserved for a prolonged period of time, as in the case of I think, I guess and you know all of which arose in Middle English (ME, hereafter). While they are still commonly used in Present-Day English (PDE, hereafter), others are known to have been lost, e.g. Old English (OE, hereafter) witodlice, ME God it woot, Early Modern English (EModE, hereafter) prithee. In general, the extensive body of research on DMs covers the whole history of English (e.g. Brinton (1996, 2008, 2010)).

This study pays attention to the fairly recent development of DMs especially from Late Modern English (LModE, hereafter) to PDE, with a special focus on the point is, based on The Corpus of Historical American English 1810-2009 (COHA, hereafter), The Corpus of Contemporary American English 1990-2012 (COCA, hereafter) and The Santa Barbara Corpus of Spoken American English (SBCSAE, hereafter), collaterally supplemented by other corpora as needed basis. Here are examples; the elements in focus are underlined for clarity.

(1) Paul admitted. "But that's not the point. The point is that there's magic in his name." $\quad(2009$, FIC, Maxxed Out; COHA)

(2) PAUL-KRUGMAN-1NEW\# "Well, sure, but, you know, the point is, though, this is, this is actually what health care reform is ultimately supposed to bring ..."

(2009, SPOK, ABC This Week, Oct. 18; COCA)

In (1), the construction the point is serves as a main clause, attached onto the following complement clause with the complementizer that; therefore, the example itself cannot be qualified as a DM: it is not syntactically independent. In (2), the point is functions as a DM, syntactically and stylistically unattached to the following clause without the complementizer that. That is, the point is can be broadly classified into two syntactic behaviours, i.e. the main clause type and the DM type (but see Section 2.3 for further discussions).

In addition, other related constructions such as the thing is, the problem is, the question is, etc. have been found to exhibit similar variations to the point is, in the history of English as well as in American conversational discourse (see Sections 2 and 4). Nevertheless, no preceding fine-grained research has paid special attention to the point is, the thing is, the problem 
is, the question is, etc. (e.g. Quirk et al. (1985), Biber et al. (1999), Huddleston and Pullum (2002)). ${ }^{1}$ Omuro (2005) explores the possibility of the grammaticalization of the fact is (that), albeit based on introspective and scant evidence (cf. Aijmer (2007)), while Suzuki and Miki (2011) provide a brief summary of "the NP is (that)" construction in general in PDE. However, they both stay within the confines of giving a broad overview of the phenomena. Therefore, the point is is worth an intensive investigation (see Section 2.1).

This study is organized as follows. Section 2 demonstrates the usage of the point is in American conversational discourse and illustrates a short history of the point is. Section 3 introduces the coding properties for the surveys of both main clause and DM types of the point is, while Section 4 provides us with the results from the corpus surveys. Section 5 gives explanations to the historical changes of the point is, along with its variant emergent constructions. Section 6 is the conclusion of this study.

\section{Background}

2.1. Frequency of The Point Is in Conversational Discourse

In relation to the similar construction the thing is, Biber et al. (1999: 448) explain that the thing occurs with be over 20 times per million words in the conversational part of their corpora, but far less in the academic portions; they go on to state that lexical bundles such as but the thing is and the only thing is are clause fragments (p. 1005). Considering that the thing is is used in the spoken genres of discourse, the usage of the point is and its related expressions in conversational discourse is also worth examination.

My conversational data come from the SBCSAE which consists of 60 conversations all among adult native speakers of American English who are friends or family members (see the next section for transcription conven-

1 There are some preceding works on the usage of "double IS" or "reduplicative copula constructions" (e.g. Bolinger (1987), Tuggy (1996), Massam (1999), Shapiro and Haley (2002), Curzan (2012)) as follows.

(i) The ratio is is that ...

(from Hillary Clinton's speech to the American Hospital Association, CNN's Early Prime news broadcast, 9 Aug. 1993; Shapiro and Haley (2002: 305))

Although their works are related to the issues addressed in this study, the double IS construction does not fall within the scope of this paper due to space limitation. See Shibasaki (under review) for a study of the thing is (that) from the perspective of "shell noun" constructions based on Schmid (2000). 
tions). Table 1 summarizes the types and tokens of "the NP is (that)" constructions in the SBCSAE.

Table 1 Types and Tokens of "the NP is (that)" Constructions in the SBCSAE

\begin{tabular}{lll}
\hline Types & Tokens \\
\hline (the) thing is (that) & 24 \\
(the) point is (that) & 4 \\
(the) problem is (that) & 2 \\
(the) fact is (that) & 2 \\
(the) question is (that) & 2 \\
(the) reality is (that) & 1 \\
(the) matter is (that) & $1^{*} \quad$ *the example is the matter of the fact is. \\
(the) reason is (that) & 1
\end{tabular}

Note that at times, the head nouns are modified by adjectivals, e.g. the whole point is or the determiner the can be replaced by others, e.g. my point is. Table 1 includes all of those variant forms for convenience as long as those examples can be considered relevant to the current discussion, accompanied by finite clauses with or without the complementizer that.

Such nouns as truth, result, idea, difference, hope, answer, trouble and danger cannot be found in this specific construction. The survey results seem to dovetail with Biber et al.'s (1999) observation because in the SBCSAE likewise, the thing is is by far the most frequent among this constructional variants. And the point is is second-ranked, which suggests that it is also worth a follow-up survey.

2.2. Discourse-Syntactic Functions of The Point Is in Conversational Discourse

Before examining the origin and development of the point is, we will take a closer look at the construction in conversational discourse, simply because whether the position of comma in written texts can staunchly reflect how language unfolds in spoken discourse cannot exactly be uncovered only by use of the COHA and COCA. That is, one cannot see where intonation break is in the representations of online deployment of English in the corpora.

In case one needs to see the actual condition, SBCSAE is useful because it is transcribed based on Intonation Units (IUs, hereafter). Chafe (1987: 22) gives a brief definition for IU: "An intonation unit is a sequence of words combined under a single, coherent intonation contour, usually pre- 
ceded by a pause"; therefore, IUs have been taken as the natural unit of discourse in either conversation or narratives. Example (3) is excerpted from the $S B C S A E$. Numbers after the SBCSAE stand for the file numbers. ${ }^{2}$

$$
\begin{array}{ll}
\text { (3) DAN: } & \text { And, } \\
\text { PATTY: } & \text {.. } \frac{\text { my [point is, }}{\text { [Some of them do, }} \\
\text { DAN: } & \text { that], } \\
\text { PATTY: } & \text { and] some of them do not. } \\
\text { DAN: } & \text {... The ones that I just mentioned do. } \\
& \text {... And, } \\
& . . \text { my -- } \\
& \ldots \text { my point is, } \\
& \ldots \text { that, } \\
& \text { it seems to us that, } \\
& \text { it- it- .. it seems to me that, } \\
& \text { it would give us= as .. Chicago, }
\end{array}
$$

As in Dan's first and second utterances, my point is, i.e. a variant form of the point is (to be discussed in later sections), is separated from the complementizer that in terms of intonation. Furthermore, Dan's third utterance produces a new revelation, i.e., the finite clause after the complementizer that is clearly separated intonationally, which is not usually part of instruction received at school (Francis (1958: 475)).

Quirk et al. (1985: 1619) strongly state that sentence elements consisting of either a phrase or a clause cannot be separated from the verb by a comma, while Quirk and Greenbaum (1973: 459) point out that a comma cannot separate a verb from its object. The following are their examples.

(4) *I know, that you are tired.

(5) *John thought, that the weather would improve.

(Quirk et al. (1985: 1619))

(Quirk and Greenbaum (1973: 459))

They bring out no examples of the point is or related constructions; howev-

2 The transcription conventions of the SBCSAE are as follows. $<$ TSK $>=$ the utterance of a click of the tongue (usually an alveolar click in English); '...'=medium pause (between 0.3 and 0.6 seconds); '..'=short pause (about 0.2 seconds or less); '--'=truncated intonation unit; '-'=truncated word; $(\mathrm{H})=$ inhalation; \%=glottal stop; [ ] $=$ speech overlap. '=' means lengthening. See Du Bois et al. (1993) for more details. Also the following are the glossing conventions in this study: $\mathrm{ADJ}=$ adjective; $\mathrm{DEM}=$ demonstrative; $\mathrm{DET}=$ determiner; $\mathrm{DM}=$ discourse marker; $\mathrm{ORD}=$ ordinal number; $\mathrm{POSS}=$ possessive; TO$\mathrm{INF}=$ to-infinitive; $\mathrm{OE}=$ Old English; $\mathrm{ME}=$ Middle English; EModE=Early Modern English; LModE=Late Modern English; PDE=Present-Day English. 
er, given that examples in (4) and (5) are disallowed due to the positions of commas, Dan's speech in (3) turns out to be peculiar also because of such comma splices. On the other hand, it was prescriptively recommended in the sixteenth century that a comma should go between a verb and its object according to Partridge (1953). With that said, the punctuation system as it stands now is to a large extent independent of the intonation system.

Two more examples of the point is are included in the $S B C S A E$ as follows.

(6) PAMELA: Mm,

DARRYL: yeah but .. but .. but=,

$\%$ to me the whole point is is,

... you have no idea,

(7) JEFF: ... (TSK) (H) Because,

(SBCSAE 005)

you see,

(90 IUs of JEFF's utterances are omitted)

.. I d- I don't care for his analogy,

but uh the point is well taken.

.. (H) Uh,

the point is that Paul does speak of the Spirit,

(SBCSAE 020)

Worth noting is that these examples co-occur with hesitation markers or hedges such as uh, but, you see as well as double copulas (is is) along with many pauses, presumably in order to frame the speaker's statement as an opinion after the point is. Viewed from a discourse-syntactic perspective, the point is seems to act as a "gambit" in the sense of Edmondson and House (1981: 69) which serves as a discourse lubricant. Furthermore, three out of the four examples in the SBCSAE appear without any other material in an IU regardless of whether the construction occurs with the complementizer that or not (see Section 4.2). This suggests that in American conversational discourse, the point is tends to be uttered intonationally unattached to the following speaker's statement, whilst habitually combined with other hedges or DMs to modalize a sequence of relevant discourse.

\subsection{A Short History of The Point Is}

The most relevant meaning of the noun point in this specific construction is described in The Oxford English Dictionary (OED, hereafter) as in (8); the earliest examples used in this construction according to the quotation survey of $O E D$ are excerpted in (9) and (10). Note that a way of analyzing prenominal modifiers such as seconde in (9) is to be introduced in Sec- 
tion $3 .^{3}$

(8) the point: the precise matter in discussion or to be discussed; the essential or important thing. (OED, s.v. point, A. 28 a.)

(9) The seconde poynte is, that there is communyon of sayntes. (1526 Pilgr. Perf. (W. de W. 1531) 218b; OED)

(10) But the point is, I know not how to better my selfe. (1602, 2nd Pt. Return fr. Parnass. v. iii. (Arb.) 68; OED, s.v. point, A. 28 a.)

Terasawa (1997: 1084) states that the meaning of point equivalent to (8) is first attested in 1385, in The Knight Tale of The Canterbury Tales. Partridge (1964: 190, fn. 3) explains that the first use of the word comma in English (c. 1530) noted by $O E D$ is from John Palsgrave, tutor to Henry VIII's daughter Mary (later Mary I), probably in his work Lesclarcissement de la langue francoyse (c. 1530); the purpose of the book was to instruct the English people in the rules of French grammar (The Columbia Encyclopedia (2001)). Furthermore, Crystal (2004: 261) notes that "The comma began to replace the virgule (/) in the $1520 \mathrm{~s}$, though some printers used them interchangeably for a while" $((/)$ is added by the present author for clarity). Judging from these observations, it is of importance to carry out additional research on the periods in Late ME through Early EModE based on other corpora.

The earliest example with the meaning in (8) is as follows. $\mathrm{HC}=$ Helsinki Corpus.

(11) The thredde poynt is age. Tat is for to seyn, a chylde of xii yeer owyn not toblede. 'The third point is age. That is to say, a twelve-year child does not have to bleed.'

(1420-1500 CMREYNES; HC Middle English Part IV) In (11), the structure of the relevant construction is 'the point is + NP' marked off with a period, which is immediately accompanied by an additional idea to supplement.

\footnotetext{
3 One anonymous reviewer states that the presence of a prenominal modifier is context-dependent, presumably due to the importance of what follows after the point is (that); I am thankful for her/his reminder. On the other hand, the point is (that) serves to point backwards as well as forwards (Aijmer (1996: 220-221)), as seen in "the third point is ..." in (11) and "the closing point is" in (18), both of which clearly depend on the preceding discourse. Such highly context-dependent usages notwithstanding, types of prenominal modifiers seem to have been skewed towards some limited sets as illustrated in Tables 2 and 3 (see also fn. 12 and 13), which reveals that this construction has become a more fixed, formulaic chunk over time.
} 
The sixteenth century onward can witness more variety in the formation of the construction; the following examples illustrate variations of relative clauses, which appears to grow in degree of hypotactic propensity, compared to (11) in Late ME. ${ }^{4}$

(12) A point..is that which have no partes.

(1559 W. Cuningham Cosmogr. Glasse 55; OED)

(13) In deliberatiues the point is what is good and what is euill.

(1597 Bacon Coulers Good \& Evill (Arb.) 138; OED)

(14) The center of the Earth is not an Attractiue, but a meere Respectiue point ..., A Respectiue point is that, which the Bodies in their motions doe respect and conforme themselues vnto.

(1625 Carpenter Geogr. Del. i. ii. 25; OED)

Concomitantly with the rise of relative clause formations, to-infinitive (TO-INF, hereafter) complements are found to have developed in this construction.

(15) a. The fyrste poynte is when a man shoulde shote, to take suche footyng and standing ...

(1545 R. Ascham Toxoph. (Arb.) 147; OED, s.v. footing, vbl. n. 4. b)

b. The fyrste poynte is .. to take suche footyng and standing ... (ibid; OED, s.v. standing, vbl. n. 2. c)

(16) The cheife and chariest point is, so to plie them all, as they may proceede voluntarily.

(1581 Mulcaster Positions v. (1887) 28; OED)

The two examples in (15) are one and the same excerpt from the common source both of which exemplify the TO-INF complement of the point is. However, worth noting is that one clause, i.e. when a man shoulde shote, is inserted between the point is and its TO-INF complement in (15a), which is obvious in (15b) in the lack of it. This would mean that there is a break in the syntax and semantics of the point is and its following complement; putting commas in an erratic way as seen in (9), (10) or (14)

\footnotetext{
${ }^{4}$ One anonymous reviewer points out the possibility that which and what in (12) through (14) may be interpreted as interrogative pronouns, for which I am obliged to her/ him. It is true that such a difference in the interpretation of given words in this transitional period can be noticed; however, those words used in the earliest examples of this specific construction show us a telling structure revealing that clauses are combined in a more hypotactic way than the earlier corresponding one in (11) irrespective of different grammatical views.
} 
might possibly reflect an actual situation where speakers pause with uncertainty to consider their words. Remember that in the SBCSAE, speakers do not state what they think or believe in a single breath but rather they utilize some hedges and hesitation markers with short pauses over a sequence of IUs to make a proposal, an offer or a conjecture (see Section 3 for related discussions). In any case, the point is can be thought to be in an immature state of development at this stage; the small number of examples is also evidence of this.

The following are the earliest examples in A Corpus of Late Modern English Texts (Extended Version) 1710-1920 (CLMETEV, hereafter).

(17) The great point is, to choose good models and to study them with care. (1750, Letters to His Son(s), Letter CI; CLMETEV)

(18) "And the closing point is, that my son is bound by his duty to me, by his honour, by every solemn tie and obligation, to marry some one else." (1841, Dickens, Barnaby Rudge(s); CLMETEV)

The example in (17) is accompanied by TO-INF, while the example in (18) can be considered the earliest example of the point is accompanied by a that-clause in CLMETEV.

In $C O H A$, the examples of the point is and its variants start from the first half of the nineteenth century, as follows.

(19) The problem to be solved in their government is presented in every government. The point is, to reconcile the greatest individual liberty, with the most perfect submission to laws.

(1835, NF, Progressive Education; COHA)

(20) He lays it down without hesitation that we proceed from particulars to universals, but the difficult point is, as Ritter says, "how cut of the lower knowledge of sense, the higher scientific knowledge is formed."

(1846, MAG, Logic; COHA)

It is interesting that, as in (19), the earliest examples are the one with a TO-INF in the COHA as well, while the example in (20) serves as the oldest one accompanied by a finite clause in the COHA. Additionally, I conducted a survey of The Helsinki Corpus of English Texts (HC, Early Modern English part 1500-1710) and A Corpus of English Dialogues (CED, 1560-1760) to search for any relevant examples; however, those corpora turned out to have no relevant examples. ${ }^{5}$

5 The Modern English Collections at the University of Virginia include several examples in as early as the sixteenth century. However, some texts are known to have 
The survey results tell us that the point is dates back to the early sixteenth century. However, the number of examples of this phenomenon is extremely sparse in the sixteenth through eighteenth centuries: one in the sixteenth century in (9) and another in the seventeenth century in (10). Judging from these observations, we feel compelled to accept that the point is itself is in an early stage of constructional development in EModE through Early LModE. ${ }^{6}$

\subsection{Interim Summary}

In this section, we have confirmed the following points. The construction the point is is the second most frequent among related constructions in the SBCSAE. In conversational discourse in the SBCSAE, the point is has a tendency to be intonationally separated from the complement to follow; at times, the complementizer that and its complement clause can even be uttered in different IUs. That is, the modern punctuation system is not always compatible with the intonation system in online spoken discourse. Historically, the construction had not yet fully developed in EModE through LModE in terms of token frequency, although the earliest example traces back to the early sixteenth century. Taking these findings into account, the constructional development of the point is deserves a thorough inquiry during the historical periods from Late LModE to PDE, which makes it meanigful to survey the use of the construction in both the $\mathrm{COHA}$ and the COCA specifically in the history of American English.

been translated in much later centuries (esp. John Calvin's; personal communication with Laurel J. Brinton 2012). Therefore, I will not use this data for this study.

${ }^{6}$ In the CLMETEV as well as the COHA, the earliest examples concerned are all unattached to the following phrases or clauses, i.e. the DM usage, as in (18) and (20). This would bring rebutting evidence against the "Matrix Clause Hypothesis" proposed in Thompson and Mulac (1991: 313; see Section 5.3). Of course, one cannot draw a quick conclusion about the syntactic origin of the construction only from a small amount of examples because stylistic or descriptive variants may possibly grow out of particular writers' own preferences. On the other hand, punctuation is very problematic once one launches a full-scale study especially with respect to syntax. That is why I devoted (a lot of space to the discussion of the interface between syntax and intonation in Sections 2.1 and 2.2 in Present-Day American English conversation. Historically likewise, the presence or absence of punctuation marks (most notably, commas) had not been stable even in LModE as discussed in Section 2.3. Although I discussed the issue, in person as well as via email, with Professor Joan C. Beal in August, 2013 (see Beal (2010) for some related issues), I will decline to discuss it any further simply because of space limitations. 


\section{Examples and Coding Properties}

In this section, we will confirm the coding properties for this study along with presenting the following examples (accessed on July 30, 2012).

(21) The point is that intellectual derangement in a musically organized person will not blunt musical sensitiveness, or disturb musical perceptions. (1878, MAG, The Nature of Music; COHA)

(22) "The point is, I hold a responsible position, ..."

(1880, FIC, The Stillwater Tragedy; COHA)

(23) But the point is, that life consists in exchange, in action and reaction. (1862, MAG, Ornament in Nature and Art; COHA)

(24) Point is, you seemed consid'able interested in the child, as one may say.

(1895, FIC, Nautilus; COHA)

(25) our only point is, that they are much less frequent in England than in other countries ...

(1847, MAG, The Social Condition of England; COHA)

As pointed out in Section 1, the main coding property centers on whether the construction the point is is directly followed by that (i.e. main clause type) as in (21) or it is unattached to the following clause, and marked off with a comma, without that (i.e. DM type), as in (22). At times, the deletion of that alone cannot serve as evidence for the division. In (23), the point is is not syntactically integrated with the following clause, and is separated by a comma, while that is not omitted; this construction is labeled as ", that-clause" as one syntactic realization of a complement (see Section 4.3). ${ }^{7}$ Those constructions in which the nominal point appears with adjectival modifiers such as important, main, only, second, etc., as shown in (25) are treated separately from the bare construction as seen in (24). The determiner-headed the point is construction as in (22) is regarded as different from the counterpart determiner-less construction as in (24). While the study centers on the historical developments of both main clause and DM types, the other two types, i.e. TO-INF and ", that-clause" complements are

7 Thompson (2002) suggests that in conversational discourse, "complement-taking predicates" such as think and know are parenthetical by their own nature regardless of whether that is present or not. In historical discourse data, however, audio data are not always available even in the recent past; therefore, this study chooses to use the abovementioned syntactic and stylistic criteria. 
illustrated as well, when relevant. ${ }^{8}$

\section{Survey Results}

\subsection{The Changes of the Main Clause and DM Types}

Figure 1 shows the vicissitudes of both main clause type (i.e. the point is that) and DM type (the point is, ...) based on their raw frequencies in the COHA; numbers in the figure stand for the raw frequency of each construction. It is clear that although the two constructions had been infrequent in the nineteenth century, the main clause type gained ascendancy over the other beginning in the early twentieth century extending up until the end of the century. At the outset of the twenty-first century, however, the DM type has switched positions with the main clause type.

Figure 1 Transitions of The Point Is That and The Point Is, ... in the COHA (accessed on 2012/11/12)

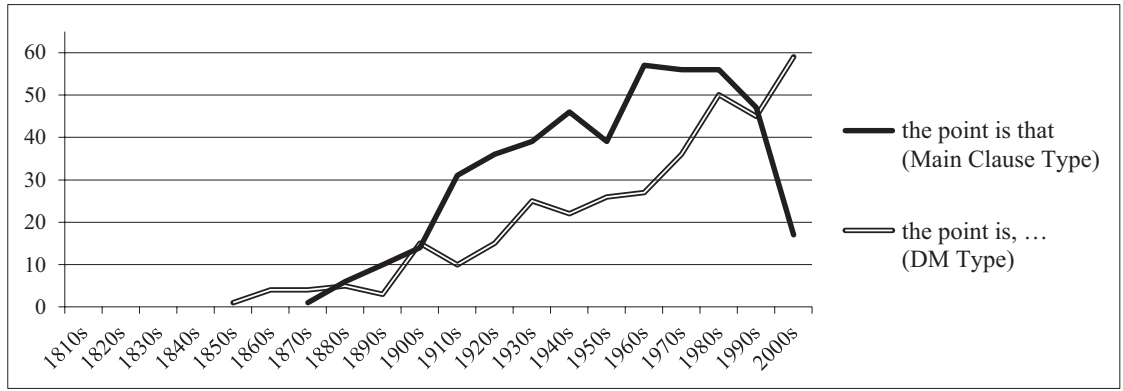

${ }^{8}$ German is known to exhibit a relatively clearer distinction between main and subordinate clauses. One way of marking a subordinate clause is the use of a subordinating conjunction with the clause; the other centers on the placement of the finite verb at the end of a given clause; these are usually combined (Imo (2011: 166)). However, in reference to Freywald (2008), Imo (2011: 167) goes on to state that "it is not uncommon to use the subordinating conjunction dass ('that') together with a verb-second main clause in spoken German." The following are such examples, in which the verbs in dass-clauses are underlined by the present author.

(i) a. Main clause plus subjunction plus main clause: Ich glaube, dass es wird heute regnen. (lit.) 'I think that it will today rain.'

b. Main clause plus main clause type: $\overline{I c h}$ glaube, es wird heute regnen.

(lit.) I think it will today rain.'

(Imo (2011: 167))

In either event, the criteria for German do not exactly work for English in a similar manner; the boundaries between main and subordinate clauses in (21) through (25) are blurred. Therefore, making our first entree into the vicissitudes of the point is that (main clause type) and the point is $\varnothing$ (DM type) would be valid in the case of English. 
Let us take a closer look at the figure. The main clause type of the point is that began to be used slightly later than the DM type, while the former had been preponderant almost consistently over the latter. However, the main clause type seems to have peaked out around the 1960s, beginning its decline which continues to the present; the steep reduction in frequency from the 1980s to the 2000s deserves attention. The DM type of the point $i s, \ldots$, on the other hand, appears to have grown almost steadily from the start of its use to this date. ${ }^{9}$

The COCA survey result has a fuller picture of the more recent situation, as shown in Figure 2. Numbers show the raw frequencies of each type. In spite of the inversion phenomenon witnessed in Figure 1, each type competes with the other in prevalence. That said, since the DM type has been dominant over the main clause type since 2006, the COCA survey goes hand-in-hand with the $\mathrm{COHA}$ survey from a larger standpoint. Note that the tokens of each type in 2012 are included in those in 2011 because COCA only covered the very early periods of 2012 when accessed for this project.

Figure 2 Transitions of The Point Is That and The Point $I s, \ldots$ in the COCA ${ }^{10}$ (accessed on 2012/11/12)

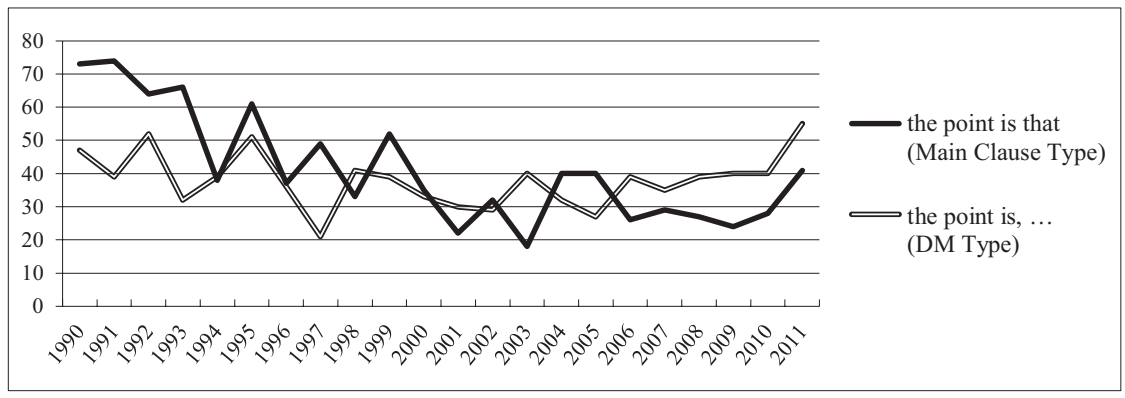

Supposing that the point is itself has been grammaticalizing as a type of construction, the predominance of the DM type the point is, ... in the recent past, which is not syntactically tied to the following clause, would be reasonable in that the point is, ... reflects 'decategorialization,' one principle

9 The differentiation of similar forms is related to the well-known dictum: "Where a speaker knows two rival forms, they differ in connotation, since he has heard them from different persons and under different circumstances" (Bloomfield (1933: 394); cf. fn. 10).

${ }^{10}$ As Biber et al. (1999) state that the thing is and its variant forms are characteristic of spoken discourse, both the point is that and the point is, ... also occur frequently in 
of grammaticalization in the sense of Brinton and Traugott (2005: 110; but see Section 5.3 and fn. 6). ${ }^{11}$ On the other hand, the nominal point in the construction can be used with pre-nominal modifiers other than the as in (25). Then, what kind of prenominal modifiers have been preferred over time in order for speakers to achieve their communicative goals? Additionally, has the construction the point is been syntactically simplified without any modifier as a case of lexicalization, which provides (dis)continuity to grammaticalization in one way or another? We will thus deal with these issues in the next section.

the spoken genre as in Chart 1 ; a variety of conversational parts sporadically found in both magazine and fiction genres result in the relatively higher frequency of both main clause and DM types. However, the academic genre presents a marked contrast in terms of frequency. The numbers on the vertical line stand for the raw frequencies; the numbers just above each column mean the normalized frequencies per million words.

Chart 1: Main Clause and DM Types of The Point Is across Genres in the COCA (accessed on 2013/12/12)

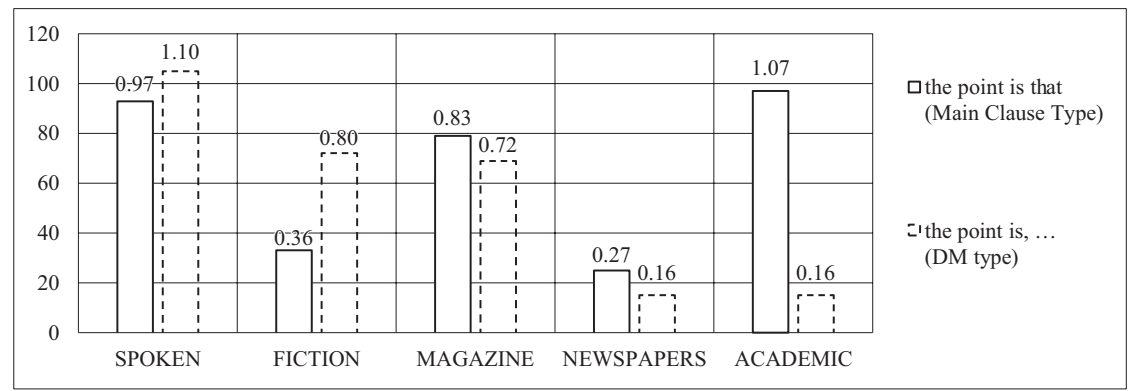

The free-standing usage of the point is, ... in discourse would look colloquial or informal in the eyes of native speakers of English; therefore, the extremely low-frequent use of the DM type in the academic genre seems to be self-evident. Nevertheless, the fact that the main clause type occurs contrastively with very low frequency in the newspapers genre does not add up at a glance; this would require additional research beyond this present study. Note that both main clause and DM types in each subsection, i.e. 1900-1994, 1995-1999, 2000-2004, 2005-2009 and 2010-2012 in COCA, show similar distributional patterns as seen in Chart 1 from a bigger perspective.

11 However, the point is, ... cannot be viewed as fully syntactically mobile because all the examples in our corpora are found to occur just in front of the speaker's statement as in the above examples, not in the clause-medial or in the clause-final position. That is, even the DM type of the point is, ... has not (yet) been grammaticalized to the extent to which the so-called "comment clauses" pivot on their syntactic mobility. 
4.2. Prenominal Modifiers for the Main Clause and DM Types

Table 2 summarizes the prenominal modifiers for both main clause and DM types in COHA. As to the main clause type, there are 76 types of prenominal modifiers; however, since the large array of those modifiers occur once or several times in the past 200 years, Table 2 epitomizes only those that are found more than 12 times. In the case of the DM type, there are 31 types of prenominal modifiers in COHA. But again, the vast majority of those occur just once in the past 200 years; therefore, Table 2 includes only those modifiers that are used more than 5 times. Notice that for each type, prenominal modifiers are aligned from the highest frequency on the left to the lowest on the right; numbers in each box indicate the token frequency of actual examples at each synchronic stage; $\varnothing$ stands for the modifier-less construction. ${ }^{12}$

There are three points in Table 2 that attract one's attention. Firstly, what collocates most frequently with the nominal point is the determiner the for both main clause and DM types; the degree of the collocationabilityi.e. the point - has become tighter in more recent years. To put it another way, the point is appears to have developed into a fixed expression regardless of the construction type, i.e., it is a case of "fusion" (Brinton and Traugott (2005: 105); to be discussed below; see Section 5.1).

12 At times, the nominal point can be modified by more than one prenominal modifier as in (25). In such cases, this study focused on the modifier just prior to the nominal point, i.e. only in (25). 
Table 2 Prenominal Modifiers for Both Main Clause and DM Types in the COHA (accessed in 2012/08/16)

\begin{tabular}{|c|c|c|c|c|c|c|c|c|c|c|c|c|c|}
\hline & \multicolumn{8}{|c|}{ Main Clause Types ${ }^{13}$} & \multicolumn{5}{|c|}{ DM Types ${ }^{14}$} \\
\hline & $\stackrel{\mathscr{E}}{\rightleftarrows}$ & ટ્ & 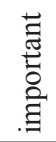 & $\stackrel{\text {. }}{\stackrel{\Xi}{\Xi}}$ & $\stackrel{\Omega}{\Xi}$ & 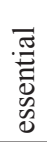 & 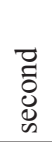 & 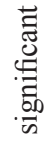 & $\stackrel{\mathscr{E}}{\rightleftarrows}$ & $\overleftrightarrow{\Xi}$ & Q & 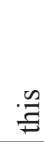 & 売 \\
\hline $1810 \mathrm{~s}$ & & & & & & & & & & & & & \\
\hline $1820 \mathrm{~s}$ & & & & & & & & & & & & & \\
\hline $1830 \mathrm{~s}$ & & & & & 1 & & & & 1 & & & 2 & \\
\hline $1840 \mathrm{~s}$ & & & & & & & & & & & & 2 & \\
\hline $1850 \mathrm{~s}$ & & & & & & & & & 1 & & & 2 & \\
\hline $1860 \mathrm{~s}$ & & & & & & & & & 4 & 2 & & 3 & \\
\hline $1870 \mathrm{~s}$ & 1 & 4 & & & 1 & 2 & & & 4 & 1 & & 1 & \\
\hline $1880 \mathrm{~s}$ & 6 & & 1 & & 2 & & & & 5 & 1 & & 2 & 1 \\
\hline $1890 \mathrm{~s}$ & 10 & 1 & & 2 & 2 & 1 & & & 3 & & 1 & & 1 \\
\hline $1900 \mathrm{~s}$ & 14 & 2 & 1 & 1 & 1 & 1 & & & 15 & 1 & & & \\
\hline $1910 \mathrm{~s}$ & 31 & 6 & 1 & 4 & 3 & 3 & & & 10 & 4 & 2 & 1 & 1 \\
\hline $1920 \mathrm{~s}$ & 36 & 5 & 2 & 3 & & & & 4 & 15 & 1 & 1 & & \\
\hline $1930 \mathrm{~s}$ & 39 & 4 & 5 & 1 & & 3 & 1 & & 25 & & 1 & & 1 \\
\hline $1940 \mathrm{~s}$ & 46 & 4 & 10 & 3 & & 1 & 4 & & 22 & 1 & & & \\
\hline $1950 \mathrm{~s}$ & 40 & 6 & 3 & 5 & 1 & 3 & 1 & 3 & 26 & & 2 & & \\
\hline $1960 \mathrm{~s}$ & 57 & 4 & 6 & 6 & 4 & 1 & 3 & 2 & 27 & 1 & & & 1 \\
\hline $1970 \mathrm{~s}$ & 57 & 3 & 5 & 2 & 2 & 1 & 5 & 1 & 35 & 3 & & & \\
\hline $1980 \mathrm{~s}$ & 56 & 10 & 7 & 3 & 3 & 1 & 1 & 3 & 50 & 3 & 4 & & \\
\hline $1990 \mathrm{~s}$ & 47 & 14 & 1 & 1 & 3 & 1 & 2 & & 45 & 5 & 1 & & \\
\hline $2000 \mathrm{~s}$ & 19 & 11 & 4 & & 2 & 1 & 1 & & 61 & 9 & 5 & & 1 \\
\hline Total & 459 & 74 & 46 & 31 & 25 & 19 & 18 & 13 & 349 & 32 & 17 & 13 & 6 \\
\hline
\end{tabular}

13 The other prenominal modifiers for the main type are as follows: whole (11 tokens), the nominal possessive -'s (11), real (10), interesting (6), his (6), present (5), first (5), key (5), crucial (4), your (4), vital (3), their (3), third (3), principal (3), next (3), bigger (2), arguable (2), another (2), Ø (2), great (2), general (2), final (2), our (2), other (2), only (2), primary (2), strong (2), theoretical (2), weak (2), weakest (1), very (1), useful (1), telling (1), technical (1), surprising (1), supreme (1), starting (1), special (1), sole (1), simplest (1), selling (1), salient (1), remarkable (1), redeeming (1), preliminary (1), practical (1), offered (1), odd (1), obvious (1), last (1), larger (1), more (1), minor (1), major (1), implicit (1), ground (1), excellent (1), fundamental (1), foremost (1), dead-sure (1), cynical (1), critical (1), clear (1), certain (1), central (1), blue (1) and a (1).

14 The other prenominal modifiers for the DM type are as follows: second (4 tokens), that (3), de (2) (< the, in some vernacular dialects of English in North America, for example, in Newfoundland (Kirwin (2001: 449)), interesting (2), only (2), one (2), real (2), whole (1), west (1), weak (1), third (1), simple (1), salient (1), present (1), our (1), obvious (1), next (1), moot (1), last (1), important (1), immediate (1), exact (1), difficult (1), crucial (1), any (1) and the nominal possessive -'s (1). 
Secondly, the modifier-less construction-i.e. point is-becomes thirdranked for the DM type, which may probably stem from the result of innumerable communicative acts in everyday interaction: the more frequently one item is used, the more likely it undergoes morphosyntactic reduction i.e. "coalescence," viewed from the perspective of grammaticalization (Brinton and Traugott (2005: 105), Bybee (2007: Ch. 7), Haspelmath (2011)). In addition, the syntactically stand-alone type-i.e. the DM type here-may facilitate the degree of coalescence at a faster rate than the main clause type (see Linell (2005) for related issues).

Thirdly, the rise of my point is to the second place for both main clause and DM types deserves consideration. Of particular note is that the first person possessive construction has moved into second place during the last few decades for each type. Judging from the examples above, the usage of the point is can be considered to let the addressee draw attention to the following statement whereby to express the speaker's stance towards what is being communicated. Given the long-term use of my point is, it follows that the speaker's subjective stance was syntactically realized as my point $i s$, whilst being differentiated from the point is in as early as the 1860s, subsequently getting conventionalized in tandem with or rather behind the development of the point is in terms of frequency. This issue is to be readdressed in Section 5.2 in relation to the emergence of other possessive constructions.

The COCA survey shows us a similar fixing or freezing of collocations with the construction as in Table 3. Although Table 3 illustrates only the top fifteen collocations for each type with their raw frequencies, it provides us with more than passing interest. For example, the top two collocations for both types-i.e. the point is and my point is-turn out to be the same as those in COHA. Furthermore, all the pronominal possessive constructions-i.e. my point, his point, your point, our point and their point-are witnessed in the past two decades. 
Table 3 Prenominal Modifiers for Both Main Clause and DM Types in the COCA (accessed on 2012/11/12)

\begin{tabular}{|c|c|c|c|c|c|}
\hline & Main Clause Type & Raw Freq. & & DM Type & Raw Freq. \\
\hline 1 & the point is that & 911 & 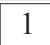 & the point is, ... & 837 \\
\hline 2 & my point is that & 190 & 2 & $m y$ point is, ... & 137 \\
\hline 3 & important point is that & 130 & 3 & $\varnothing$ point is, $\ldots$ & 36 \\
\hline 4 & this point is that & 72 & 4 & whole point is, ... & 18 \\
\hline 5 & 's point is that & 50 & 5 & second point is, ... & 17 \\
\hline 6 & main point is that & 39 & 6 & this point is, ... & 12 \\
\hline 7 & second point is that & 36 & 7 & other point is, ... & 12 \\
\hline 8 & his point is that & 35 & 8 & his point is, ... & 10 \\
\hline 9 & key point is that & 35 & 9 & main point is, ... & 9 \\
\hline 10 & whole point is that & 24 & 10 & your point is, ... & 8 \\
\hline 11 & your point is that & 23 & 11 & only point is, ... & 8 \\
\hline 12 & our point is that & 19 & 12 & important point is, ... & 6 \\
\hline 13 & other point is that & 19 & 13 & their point is, ... & 5 \\
\hline 14 & real point is that & 18 & 14 & first point is, ... & 4 \\
\hline 15 & basic point is that & 14 & 15 & 's point is, ... & 4 \\
\hline
\end{tabular}

In addition to pronominal possessive constructions, the nominal possessive counterpart, i.e. $-s$, is found to be a high-frequency item in the case of the main clause usage. Here is an example.

(26) "\# Walsh's point is that writers know how to observe. Pollin's point is that they know how to think. Wilbon figures it's simpler than that." (2003, NEWS, USA Today, Sports; COCA) In (26), the two third persons' opinions are used contrastively with Walsh's and Pollin's, respectively. Presumably, the non-first person's possessive use can be triggered by the highly frequent use of the first person possessive construction. It is true that some forms have been fixed as frozen forms such as the point is in terms of frequency; however, the emergence of a variety of possessive forms appears to indicate the broadening of the horizons of constructional generality (see Section 5.1).

Importantly, what seems to be the third party's opinion at first glance proves to be the projection of the speaker's stance toward the addressee's or the third party's point of view. Consider the examples to follow.

(27) “... but I think Burke's point is that stylistics is now a rich enough field for study that a single semester it is not enough for most students."

(2004, ACAD, Style, winter 2004, vol. 38 (4); COCA) 
(28) "It's linked to real changes in these economies. But I think your point is that whether it's the IMF or my institution, the World Bank, that we somehow contribute to moral hazard ..." (1997, SPOK, ABC This Week, Dec. 28; COCA)

The comment clause $I$ think serves to change the look of the whole sentence. In (27), the content of the anchor clause is the speaker's personal view, albeit resorting to Burke's point is; in (28) likewise, the speaker summarizes what the addressee is assumed to think of the current issue by using your point is, while combining the your point is that clause with another fragment $I$ think to make the whole utterance (Hopper (2004: 153); see Hopper's (1998) concept of “Emergent Grammar").

All in all, among a set of related constructions, some are fixed and stable, while others are in a state of flux, as shown in Tables 2 and 3 (see Section $5.2)$.

\subsection{Types of Complements}

As shown in Section 2, several types of complements are found to cooccur with the point is: a ", that-complement" clause in (9), a TO-INF complement in (15), that-which type in (12) and what type in (13). Complement types are reported to vary according to historical stages (De Smet and Cuyckens (2005), De Smet (2012)) and even in one synchronic stage (Van Bogaert (2011)) because variations directly follow and reflect how speakers use language (see fn. 9).

Figure 3 summarizes the transitions of the four types of complements based on their raw frequencies. "Ø-clause" stands for the complementizerless finite clause as in (22); "that-clause" indicates a clause directly linked by that as in (21), while ", that-clause" means a clause separated by a comma as in (23); "TO-INF" indicates a clause in which the point is takes a TO-INF complement as in (17), regardless of whether there is a comma between them or not. It is clear that "that-clauses" had been predominant from the 1880s to the 1990s and dropped sharply in the 2000s; this is the same result as was found for the vicissitude of the point is that in Figure 1. On the other hand, "Ø-clauses" got ahead of "that-clauses" in the 2000s, probably in tandem with the steady penetration of the DM type of the point is, ... as shown in Figure 1. While ", that-clauses" as well as TO-INF complements appeared earlier than "Ø-clauses" and "that-clauses," they are still used relatively with low frequency. 
Figure 3 Transitions of Complement Types in the $\mathrm{COHA}$ (accessed on 2012/11/12)

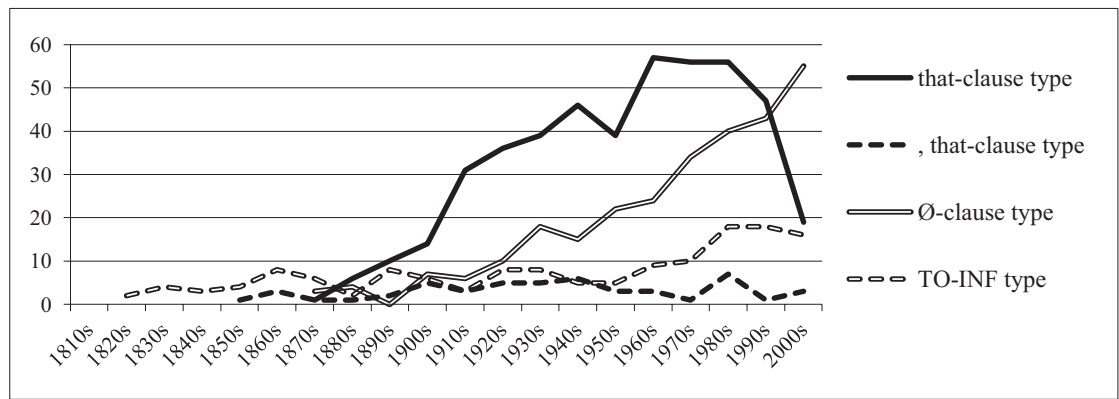

As for the COCA, the transition of complement types is summarized in Figure 4, which gathers and analyzes more detailed information especially concerning the vicissitudes of "that-clauses" and "Ø-clauses" in head-tohead competition. Numbers on the vertical line indicate their raw frequencies.

Figure 4 Transitions of Complement Types in the COCA (accessed on 2012/11/12)

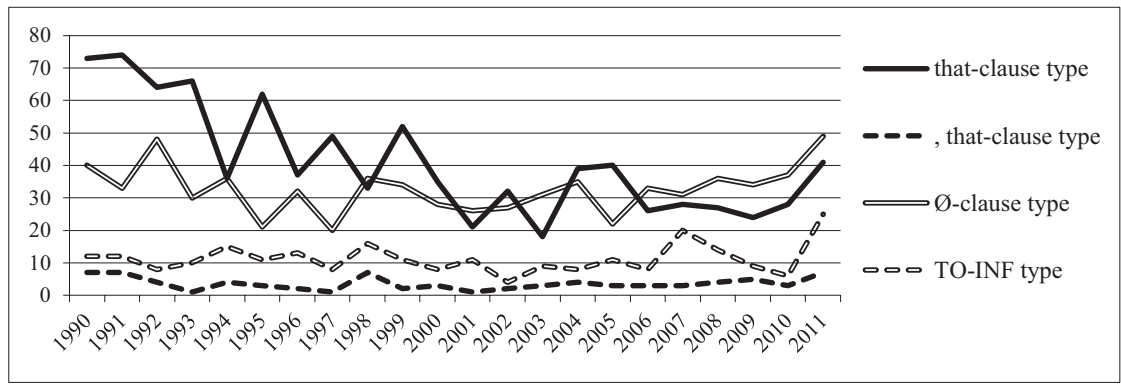

Contrary to the outcomes of the COHA survey, the actual transitional changes of "that-clauses" and "Ø-clauses" turn out to be in a close race with each other. Although "Ø-clauses" seems to have won the close game, "that-clauses" still remain fairly frequent. Relatively infrequent as they are, both ", that-clauses" and "TO-INF" complements have been used on a continuous basis. Both "that-clauses" and "Ø-clauses" preponderate in terms of frequency, probably due to the close associations, respectively, with the main clause type of the point is that and the DM type of the point is, ... Productivity varies according to types of constructions and to their correlative relations. 


\subsection{Interim Summary}

In this section, we have confirmed the following points based on the COHA and the COCA. Firstly, the construction seems to have arisen around the mid-nineteenth century, first as a DM type and then as a main clause type. While both types have ever since competed with each other, the DM type is currently predominant in frequency. Secondly, the determiner the has a strong tendency to co-occur with the construction as a prenominal modifier, while many other modifiers are used on an ad hoc basis, and were just found once in the data. Thirdly, the first person possessive constructions, i.e. my point is that and my point is, ..., show a rise in frequency and have become second-ranked in the past few decades. The reason why my point is becomes the second most frequent expression lies in the reflection of the speaker's subjectivity toward the current issue in discourse; even in the case of either second or third person possessive construction, the content of the following anchor clause results in the prominence of the speaker's liberal but subjective interpretation, often realized with comment clauses, e.g. I think as in (27) and (28). Fourthly, types of complement following the point is exhibit variations in productivity, while "that-clause" and "Ø-clause" types are much more frequent than the other two, i.e. ", that-clause" and "TO-INF" types.

In the next section, we will give an in-depth analysis of what was found in this section from the perspective of grammaticalization.

\section{Discussion}

In this section, we will make an extensive and detailed analysis of the following three aspects of the grammaticalization of the point is, based on the survey results in Section 4. Firstly, we regard the grammatical variations and change of the point is as a case of constructional grammaticalization. Secondly, we bring our attention to one of the meso-constructional variations, i.e. the possessor-headed construction, with a focus on the highly frequent micro-construction my point is; we associate it with syntactic subjectivity. Thirdly, we briefly deal with the origin and the process of the point is, seeing whether the constructional expansion dovetails with the socalled "Matrix Clause Hypothesis" (Thompson and Mulac (1991: 313)).

\subsection{Constructional Grammaticalization}

The discourse-syntactic structure that characterizes the point is at all its historical periods has the strong tendency to appear in front of the speaker's 
statement as in (29).

(29) LEE: Do you have more big novels in you?

NM: I don't know, I hope so. The point is, one of the things that happens when you get older is your command of your vocabulary begins to diminish.

(2007, NF, The Devil in Norman Mailer; COHA)

Occasionally, some hedges step in either before or after the point is as in (30) through (32); however, the point is does not appear after anchor clauses in my database.

(30) MR-PLOUFFE: But the point is, and I think the fundamental question is, we just came through this ... (2012, SPOK, NBC Meet Press; COCA)

(31) ENRIQUE: Absolutely. And I think that the point is, you know, you can go to Cape Cod or ...

(2011, SPOK, NPR Talk Nat; COCA)

(32) “... it's because the paintings, they are actually valuable. The point is, I mean, that's why-that's why."

(2009, SPOK, NBC Today; COCA)

Taking into account the fact that the point is can be uttered in a strident tone of voice at times, hedges may serve to soften the speaker's whole utterance, with tact and consideration or to attract attention like mind you, depending on the person one is speaking to in discourse. In this sense, the point is in its entirety modalizes the host clause to follow.

Now, let us discuss the discourse-syntactic representation of the point is, as pictured in (33), where the acquisition of discourse functions goes in tandem with grammaticalization.

(33) The Discourse-Syntactic Representation of The Point is $[$ the point is + the speaker's statement ] discourse \{preliminary remark\} \{main (source of) information $\}$ function

The position of the point is in this syntactic sequence is discourse-interactive, serving as a prologue to the main (source of) information that immediately follows. In addition, in that the speaker pauses a moment before $\mathrm{s} / \mathrm{he}$ states her/his own statement, the point is can be thought to involve the consideration of tact or be a strategy of politeness: once the addressee hears the construction, s/he can easily get prepared for the speaker's statement to follow. In this regard, the point is follows a predictable pattern that facilitates the speaker-hearer interaction in immediate discourse; what is cataphorically expressed is announced by the construction.

According to Croft (2001), constructions are symbolic form-meaning 
pairings and (parts of) constructions form a network whereby elements are taxonomically related and connected. Concerning the relation between constructions and grammaticalization, Traugott (2003: 624) specifies that “... early in grammaticalization, lexemes grammaticalize only in certain highly specifiable morphosyntactic contexts, and under specifiable pragmatic conditions." 15 I thus argue that the point is is a construction that inherits properties from higher up in the taxonomy, i.e. the NP is (that).

Figure 5 shows a constructional taxonomy of the point is based on the outcomes of this study. Note that since this study gives priority to main clause and DM types, micro-constructions for ", that-clause" and "TO-INF" types are left out.

Constructional variations can be rendered in a highly specific syntactic structure in discourse as in (33); this discourse-syntactic structure serves as a superordinate construction, which facilitates the formation of mesoconstructions, subsequently giving rise to micro-constructions. However, not all meso- and micro-constructions are necessarily or equally entrenched: constructional productivity is heavily skewed towards some particular mesoand micro-constructions (see Section 5.2 for further discussion).

15 Hopper (2011: 30) states similar comments on the use of such a/an construction in the SBCSAE: "all examples of the (a) such a/an construction terminate in the full stop intonation symbolized in the transcription by a period" (p. 30) as in (i), "which licenses the interlocutor to begin a turn if she wishes to (a transition-relevance place). The (b) type of the such a/an construction is bi-clausal" as in (ii). "Here, the sequence such a/ an anticipates (projects) a second clause which usually begins with that. The meaning is resultative: the second clause follows as a result of the first clause" (p. 30). See Traugott and Trousdale (2014) for related issues.

(i) $(\mathrm{H})$..we had such a nice day.

(ii) (H) And he was such a hit there, that Macy's gave him his very own charge card.

(Hopper (2011: 30)) 


\section{Figure 5 A Constructional Taxonomy of The Point Is}

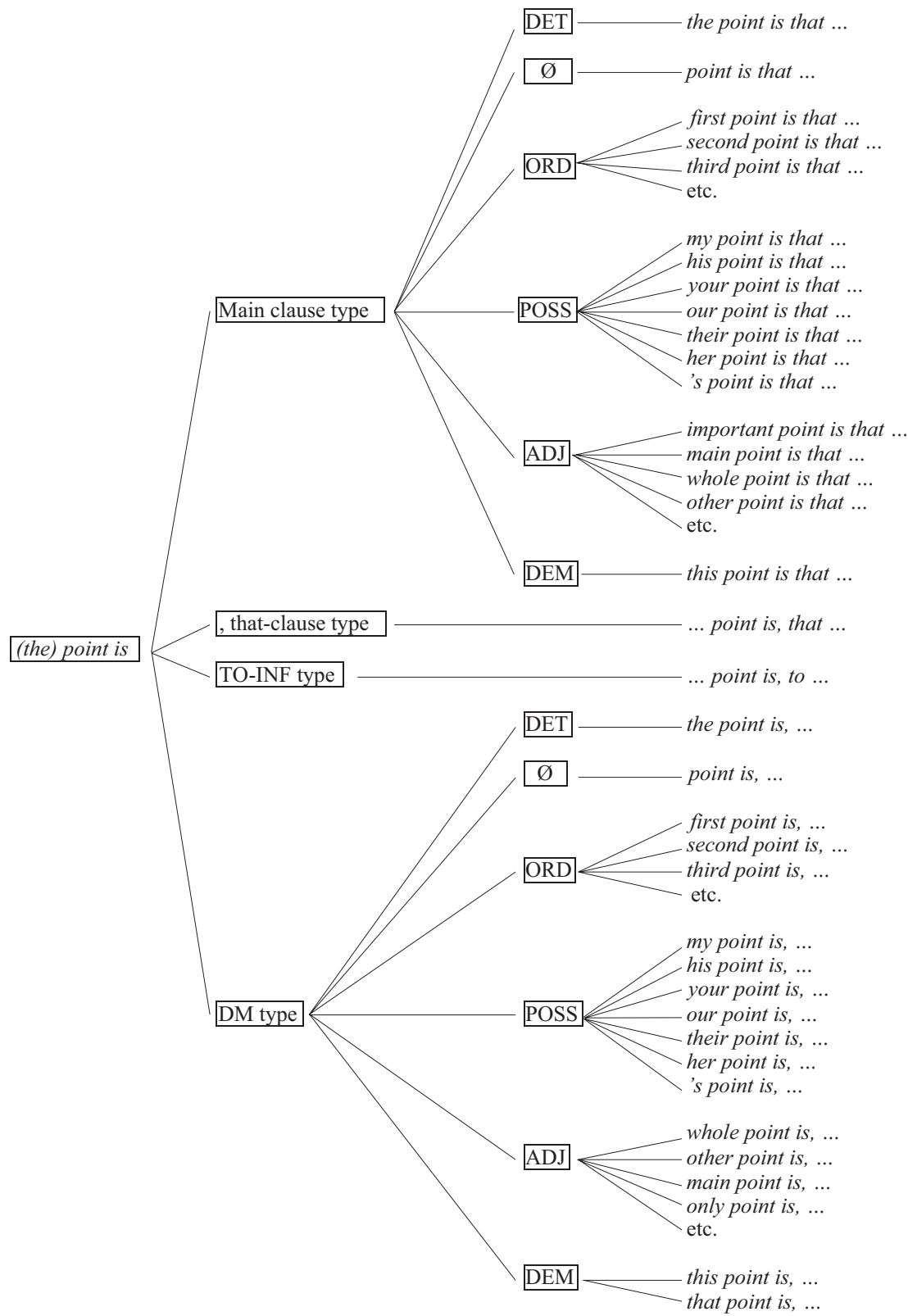

Macro

Meso

Micro 
For example, the determiner-modified the point is construction is no doubt a highly frequent construction, while some adjective-modified and ordinalnumbered constructions (e.g. cynical point is, fourth point is) are sparsely distributed or out of date as of the present; the determiner-less construction ( $\varnothing$ point is) is found mostly in the DM type (36 examples in the COCA and 17 in the $\mathrm{COHA}$ ) but not frequently in the main clause type (1 example in the COCA and 2 in the COHA). In short, while constructions can be characterized by a certain degree of generality, they lack internal fixation (Van Bogaert (2011: 308-315); cf. Sections 2.3 and 3 for related discussions).

Furthermore, the point is can be considered to be an on-going or rather on-coming phenomenon compared to other well-known cases of grammaticalization; one cannot be quite sure whether the present variations converge into a couple of more fixed chucks such as the point is and $\varnothing$ point is or whether those variations continue to render further constructional variations. Nevertheless, since constructions are formed and progress in a network not in isolation, putting a construction in a wider taxonomy and examining its relation to other constructions of higher up or lower down in schematicity enable language users to create and recreate grammar.

In the next section, we will scrutinize one particular set of constructions, i.e. the pronominal possessive constructions, and demonstrate that constructions progress in a network.

\subsection{Syntactic Manifestations of Subjectivity}

In this section, we will cast a spotlight on the pronominal possessive constructions, e.g. my point is, your point is, his point is, etc., with emphasis on how each person construction developed with respect to the person hierarchy. Language can be regarded as a reflection of constant negotiation between the speaker and the hearer, so it would not be surprising if some speaker-based principles play a role in language change (e.g. Traugott (2003), Krug (2012)). Croft (2003: 289) states that "languages don't change; people change language." If we take language change as being discourse-based, the following statement is also worth paying attention to: "Yesterday's discourse is today's language; today's discourse is tomorrow's language" (Roberts (1944: 299)). In all likelihood, language change is speaker-based, probably evidenced by discourse frequency (Krug (1998)). The most remarkable aspect of the speaker's involvement in this particular construction is associated with the rise of the possessive my. If language change is truly speaker-based, the highly frequent usage my point is would likely have triggered a chain of inner constructional expansion, 
arguably exhibiting person hierarchy effects, resulting in the emergence of other possessive constructions.

Table 4 summarizes the earliest examples of the first, second and third person possessive constructions, based on the COHA, the COCA, the $C L$ METEV and the HC (Early Modern English part 1500-1700).

Table 4 The Constructional Expansion of POSS + NOUN + is

\begin{tabular}{|l|l|l|l|}
\hline Examples & $\begin{array}{l}\text { The Earliest 1st Person } \\
\text { Usage }\end{array}$ & $\begin{array}{l}\text { The Earliest 2nd } \\
\text { Person Usage }\end{array}$ & $\begin{array}{l}\text { The Earliest 3rd Person } \\
\text { Usage }\end{array}$ \\
\hline mod. + opinion is ... & 1732 (my), 1823 (our) & 1961 & 1845 (his), 1869 (their) \\
\hline the answer is ... & 1828 (my), 1844 (our) & 1864 & $\begin{array}{l}1836 \text { (his), 1887 (their) } \\
1960 \text { (her) }\end{array}$ \\
\hline the reason is ... & 1828 (my) & $\ldots$ & 1931 (their), 1938 (his) \\
\hline the question is ... & 1837 (our), 1868 (my) & 1914 & 1977 (his, her), 1999 (their) \\
\hline the point is .. & 1860 (my), 1909 (our) & 1956 & $\begin{array}{l}1893 \text { (his), 1929 (their) } \\
1999 \text { (her) }\end{array}$ \\
\hline the problem is ... & 1895 (my), 1921 (our) & 1955 & $\begin{array}{l}1961 \text { (their), 1963 (his) } \\
2004 \text { (her) }\end{array}$ \\
\hline the thing is ... & 1993 (my) & $\ldots$ & $\begin{array}{l}2000 \text { (her), } 2005 \text { (his) } \\
2007 \text { (their) }\end{array}$ \\
\hline the truth is ... & $\ldots$ & $\ldots$ & $\ldots$ \\
\hline the fact is ... & $\ldots$ & $\ldots$ & $\ldots$ \\
\hline the result is ... & $\ldots$ & $\ldots$ & $\ldots$ \\
\hline
\end{tabular}

In close association with the construction "POSS point is," Table 4 includes the survey results of other related constructions with the aim of identifying certain key directions of change at the level of a superordinate construction, i.e. POSS + NOUN + is. Note that the earliest examples are listed in Table 4 despite their different types of complements because we direct our attention to the historical development and order of pronominal possessive constructions. Each construction is aligned according to the earliest dates of the first person possessive ones for convenience sake; mod. $=$ modifier.

Out of the ten constructions, five offers a paradigmatic set of possessive constructions, while the truth is, the fact is and the result is have not (yet) developed even the first person possessive construction; the thing is and the reason is have derived their first and third person constructions but not (yet) their second person forms. ${ }^{16}$ Nevertheless, the overall direction in the

16 One reviewer knowledgeably points out that such nouns as truth, fact and result are unlikely to or cannot be connected with $m y$, which s/he further argues is a truism; 
emergence of the possessive constructions is from first person to non-first person, which acts in concert with the speaker-based triggering of constructional expansion. Therefore, the general trend in constructional expansion can be summarized as in (34).

(34) The Direction of Constructional Expansion: POSS $+\mathrm{NOUN}+$ is first person $>$ non-first person

Worth noting is that although some constructions are used in the form of the + NOUN $+i s$ ( + that) in the corpora, their possessive constructions have not yet emerged, which would tell us that some lexical meanings of particular nouns are associated more directly with the speaker's stance.

Building on these observations, we could draw a conclusion that the

I am grateful to her/his constructive criticism. In fact, Aijmer (1996: 221-222) summarizes a variety of discourse markers with respect to the speaker-hearer deictic orientation in discourse and argues that the fact is is neither speaker/hearer-oriented nor third-party oriented. Her argument turns out to be true, especially so given that the survey results in Table 4 are taken into account: *my fact is (that), *your fact is (that), *his fact is (that), etc. Be that as it may, both native and non-native speakers of English obviously continue to expand the horizons of this particular construction. For example, a careful survey of The Corpus of Global Web-Based English (GloWbE) provides us with some but not many examples that run counter to either theoretical forecasts or introspection. The following are only about truth, fact and result (accessed on 2013/12/12).

(i) \#My fact is the Jaguar Skills album is not even out yet!

(2012/08/13, Blog, Great Britain; GloWbE)

(ii) \#My truth is that I am blessed by the gift of bestowal and production;

(2010/06, General, United States; GloWbE)

(iii) \#But our truth is that present day Tanzanian politicians lack the wherewithal to master our potential for the greater good.

(2012/08, General, Tanzania; GloWbE)

In total, GloWbE includes 1 example of $m y$ fact is (accompanied by a finite clause) in Great Britain, 5 examples of my truth is (that) in Canada (1 token), Kenya (1) and United States (3), 2 examples of our truth is that in Tanzania (1) and United States (1), and 1 example of their truth is that in Malaysia; however, no possessor-marked examples of result is (that) are found in the corpus. Notice that at times the corpus does not identify the dates of the examples.

The result of this corpus survey tells us that once one finds a usage of the first person singular possessive marker in one particular construction, s/he would likely find other forms of realization, i.e. my truth is (that), our truth is (that) and their truth is (that). In short, the general trend in constructional expansion according to the person hierarchy in (34) is still valid for this particular construction.

Theoretically and descriptively as well, Aijmer (2013: 3) states that "'new' pragmatic markers (or uses of pragmatic markers) travel quickly to other varieties" in reference to Mair (2009: 22) who demonstrates that be like, an innovation in American English, is now reported as an innovation in Australian and Canadian English. Presumably, "the NP is (that)" is also one of the fastest-spreading constructions in English today. 
POSS + NOUN + is construction advances in cooperation and coordination with the (increasing) degree of the speaker's subjectivity, gradually expanding the paradigmatic range of the construction. Trousdale (2008) mentions that an increase in productivity is a key feature of the nature and development of a construction, and our investigation results lend validity to his claim. More to the point, the speaker's involvement in language change raises productivity in a network.

\subsection{From Parenthetical to Main Clause}

Finally, we will briefly rethink one direction of change common among most "(the) NOUN is (that)" constructions, however, which runs counter to what is believed in the field of grammaticalization research, i.e. the directional change from main clause to $\mathrm{DM}$, as reported in a variety of preceding studies (e.g. Thompson and Mulac (1991), cf. Brinton (2008: 249250)). As discussed in Sections 2 and 4, the earliest example of the point is had a DM or parenthetical usage, marked off with a comma, as in the point is, that-clause. Then later, this discourse-syntactic structure brought about two streaky structures: one is the emergence of the point is thatclause (i.e. main clause type), while the other is the emergence of the point is, $\varnothing$-clause (i.e. DM type without that), as shown in Section 4.3. These are schematized as follows.

$$
\text { (35) the point is, that ... (c. 1526) }>\left\{\begin{array}{l}
\text { the point is that ... (c. 1878) } \\
\text { the point is } \varnothing \ldots \text { (c. 1602) }
\end{array}\right\}
$$

The direction of change from the point is, that ... to the point is $\varnothing \ldots$ can be regarded as a typical case of grammaticalization because the process exemplifies syntactic simplification. However, the direction of change from the point is, that ... to the point is that ... reflects "syntactic tightening" because the point is takes on a new dimension as a "main clause." Bybee (2001) states that main clauses are innovative while subordinate clauses are conservative; her arguments prove to be much to the point from a crosslinguistic perspective (e.g. Dehé and Kavalova (2007), Schneider (2007), Brinton $(2008,2010))$. However, what Bybee (2001) points out is not a syntactic tightening of main clauses but a functional expansion of main clauses, for example, as seen in the advent of comment clauses. On the other hand, what this study uncovered-i.e. the process from parenthetical to main clause - has received but scant attention; it is in direct conflict with the outcomes of grammaticalization research. As a consequence, it has not come under close scrutiny. 
Of course, an accurate grasp of language change in general is useful for making an accurate estimate of what happened, what is going on and what will happen in the history of a given language. For example, Omuro (2005) provides us with the following examples based on Bolinger (1972).

(36) a. The fact is that nobody knows.

b. The fact is, nobody knows.

(Bolinger (1972: 67); cited in Omuro (2005: 132))

Omuro's (2005) argument remains within the bounds of introspective studies due to the lack of a sufficient amount of actual data. Nevertheless, his hypothetical formulation of the constructional expansion from (36a) to (36b) is consonant with the historical facts as in (37) through (39), although the greatest care must be taken in dealing with examples from the same author (cf. fn. 6).

(37) But the fact is that opportunities very inviting to such an attempt have offered;

(1770, Edmund Burke, Thoughts on the Present Discontents; CLMETEV)

(38) The fact is, that they did thus apply those general arguments; (1775, Edmund Burke, On Conciliation with America; CLMETEV)

(39) The fact is, you yourself are to blame for it.

(1791, Robert Burns, The Letters of Robert Burns; CLMETEV)

That being said, the actual process of constructional change may still be beyond all expectations; the point is followed a different path of change as in (35), while the thing is developed: the thing is, Ø ... (c. 1796-1801) > the thing is, that ... (c. 1821-22) > the thing is that ... (c. 1920) according to Shibasaki (under review). As of 2013, a good portion of (the) NOUN is (that) constructions illustrate the similar constructional variations to those of the point is shown in Figure 5. However, the vicissitudes of complement types especially at the dawn of constructional expansion is neither regular nor unidirectional, which does not necessarily give full support for a theory of grammaticalization.

As I conceded at the beginning of this section, I kept to a minimum what has been surveyed with respect to this specific aspect of (the) NOUN is (that) because the process of the constructional change is still a process steeped in mystery. However, the possibility that the point is began with a parenthetical function must be considered in view of grammaticalization. 


\section{Concluding Remarks}

In this study, I made a thorough investigation of the point is especially in the history of American English, and presented the following survey results. Firstly, the two main functions of the point is -i.e. main clause and DM types - have been in rivalry to the present; after the turn of the twentyfirst century, the DM type is superior in number to some extent. Secondly, types of complements have also been competitive; specifically, a syntactically tightened that-complement type and a stand-alone Ø-complement type have been preponderate in terms of frequency, probably pertaining to their counterparts, main clause and DM types. Thirdly, among various prenominal modifiers, the nominal point has a strong preference for the determiner the over the others; the large array of prenominal modifiers are found to be used if need be. All these three results tell us that the grammaticalization process is not exactly a solid freezing of one particular construction but rather a constellation of constructions that vary in productivity as the case may be. Fourthly, the rise of the first person possessive construction my point is has some bearing on the increase of subjectivity; since any syntactic reflection of subjectivity has not been the focus of a discussion in the majority of grammaticalization studies (cf. Company (2006)), the thriving of this syntactic phenomenon in the fairly recent past would give a fresh insight into grammaticalization theory. Fifthly, the historical development of the point is is from a parenthetical to a main clause and from a parenthetical to a DM, as in (35). From another theoretical point of view, the former direction of change does not come to terms with the claims of grammaticalization research, while the latter direction of change can be anticipated according to the theory. Furthermore, the changing directions of all the (the) NOUN is (that) constructions have been varying according to the lexical types of each head noun, as explained above. All in all, the history of the point is provides us with the variability of language that would challenge attention and create controversy in the framework of grammaticalization but that would become the focus of attention in historical pragmatics (Jucker and Taavitsainen (2013: 5-10)).

Although the construction the point is appeared in the early sixteenth century, the explosive increase in frequency started at the turn of the nineteenth and twentieth centuries, which can be regarded as part of LModE. Traditionally, LModE seems not to have drawn the special attention of English historical linguists, as seen in the statement that "The linguistic changes that have taken place from the eighteenth century to the present day are relative- 
ly few" (Freeborn (1992: 180)). On the other hand, Beal et al. (2012: 206) argue that the corpus revolution for LModE studies have facilitated studies in syntax and pragmatics in the period. In fact, the recent highly visible research orientation to LModE (e.g. Beal (2004), Kytö et al. (2006), Mair (2006), Tieken-Boon van Ostade (2008, 2009), Tieken-Boon van Ostade and van der Wurff (2009)) is worthy of serious consideration.

Keeping pace with or a few paces behind with the above-mentioned achievements, I also demonstrated several interesting but highly complex issues in the development of the point is, which has been passed over unnoticed even in fine-grained works on LModE or in English historical linguistics in general. Therefore, it goes without saying that LModE is still a great open space yet to be explored, albeit on the doorstep of the wellexplored stage, i.e. PDE. Wyld (1936: §186) clearly says that "This period offers ample scope for investigation. It is no exaggeration to say that a proper history of each of these centuries has yet to be written." Apparently, English is still full of untapped resources, and the history of the point is is good proof of this.

\section{REFERENCES}

Aijmer, Karin (1996) Conversational Routines in English, Longman, London.

Aijmer, Karin (2007) "The Interface between Discourse and Grammar: The Fact is that," Connectives as Discourse Landmarks, ed. by Agnès Celle and Ruth Huart, 31-46, John Benjamins, Amsterdam.

Aijmer, Karin (2013) Understanding Pragmatic Markers, Edinburgh University Press, Edinburgh.

Beal, Joan C. (2004) English in Modern Times 1700-1945, Arnold, London.

Beal, Joan C. (2010) "The Grocer's Apostrophe," English Studies 102, 57-64.

Beal, Joan C., Susan Fitzmaurice and Jane Hodson (2012) "Introduction: Late Modern English - the State of the Art," English Language and Linguistics 16, 201-207.

Biber, Douglas, Stig Johansson, Geoffrey Leech, Susan Conrad and Edward Finegan, eds. (1999) Longman Grammar of Spoken and Written English, Longman, London.

Bolinger, Dwight (1972) That's That, Mouton, The Hague.

Bolinger, Dwight (1987) "The Remarkable Double IS," English Today 9, 39-40.

Bloomfield, Leonard (1933) Language, Allen \& Unwin, London.

Brinton, Laurel J. (1996) Pragmatic Markers in English, Mouton de Gruyter, Berlin.

Brinton, Laurel J. (2008) The Comment Clause in English, Cambridge University Press, Cambridge. 
Brinton, Laurel J. (2010) "Discourse Markers," Historical Pragmatics, ed. by Andreas H. Jucker and Irma Taavitsainen, 285-314, De Gruyter Mouton, Berlin.

Brinton, Laurel J. and Elizabeth C. Traugott (2005) Lexicalization and Grammaticalization, Cambridge University Press, Cambridge.

Bybee, Joan (2001) "Main Clauses are Innovative, Subordinate Clauses are Conservative," Complex Sentences in Grammar and Discourse, ed. by Joan Bybee and Michael Noonan, 1-17, John Benjamins, Amsterdam.

Bybee, Joan (2007) Frequency of Use and the Organization of Language, Oxford University Press, Oxford.

Chafe, Wallace (1987) "Cognitive Constraints on Information Flow," Coherence and Grounding in Discourse, ed. by Russell Tomlin, 21-55, John Benjamins, Amsterdam.

Company, Company C. (2006) "Zero in Syntax, Ten in Pragmatics," Subjectification, ed. by Angeliki Athanasiadou, Costas Canakis and Bert Cornille, 375-397, Mouton de Gruyter, Berlin.

Croft, William (2001) Radical Construction Grammar, Oxford University Press, Oxford.

Croft, William (2003) Typology and Universals, 2nd ed., Cambridge University Press, Cambridge.

Crystal, David (2004) The Stories of English, The Overlook Press, Woodstock.

Curzan, Anne (2012) "Revisiting the Reduplicative Copula with Corpus-Based Evidence," The Oxford Handbook of the History of English, ed. by Terttu Nevalainen and Elizabeth C. Traugott, 211-221, Oxford University Press, Oxford.

De Smet, Hendrik (2012) Spreading Patterns, Oxford University Press, Oxford.

De Smet, Hendrick and Hubert Cuyckens (2005) "Pragmatic Strengthening and the Meaning of Complement Constructions," Journal of English Linguistics 33, 3-34.

Dehé, Nichole and Yardanka Kavalova, eds. (2007) Parentheticals, John Benjamins, Amsterdam.

Du Bois, John W., Stephen Schuetze-Coburn, Susanna Cumming and Danae Paolino (1993) "Outline of Discourse Transcription," Talking Data, ed. by Jane A. Edwards and Martin D. Lampert, 45-89, Lawrence Erlbaum Associates, New Jersey.

Edmondson, Willis and Juliane House (1981) Let's Talk and Talk about IT, Urban and Schwarzenberg, München.

Francis, Nelson W. (1958) The Structure of American English, The Ronald Press Company, New York.

Freeborn, Dennis (1992) From Old English to Standard English, Macmillan, Basingstoke.

Freywald, Ulrike (2008) "Zur Syntax und Funktion von dass Sätzenmit Verbzweitstellung," DeitscheSprache 36, 246-285.

Haspelmath, Martin (2011) “The Gradual Coalescence into 'Words' in Grammaticalization," The Oxford Handbook of Grammaticalization, ed. by Heiko Narrog and Bernd Heine, 342-355, Oxford University Press, Oxford. 
Hopper, Paul (1998) "Emergent Grammar," The New Psychology of Language, ed. by Michael Tomasello, 155-175, Psychology Press, Mahwah.

Hopper, Paul (2004) "The Openness of Grammatical Constructions," CLS 40, 153175.

Hopper, Paul (2011) "Emergent Grammar and Temporality in Interactional Linguistics," Constructions, ed. by Peter Auer and Stefan Pfänder, 22-44, De Gruyter, Berlin.

Huddleston, Rodney and Geoffrey K. Pullum (2002) The Cambridge Grammar of the English Language, Cambridge University Press, Cambridge.

Imo, Wolfgang. (2011) "Clines of Subordination-Constructions with the German 'Complement-Taking Predicate' glauben," Subordination in Conversation, ed. by Ritva Laury and Ryoko Suzuki, 165-190, John Benjamins, Amsterdam.

Jucker, Andreas H. and Irma Taavitsainen (2013) English Historical Pragmatics, Edinburgh University Press, Edinburgh.

Kirwin, William J. (2001) "Newfoundland English," The Cambridge History of the English Language, vol. VI, ed. by John Algeo, 441-455, Cambridge University Press, Cambridge.

Krug, Manfred (1998) "String Frequency," Journal of English Linguistics 26, 286320.

Krug, Manfred (2012) "Early Modern English," English Historical Linguistics, vol. I, ed. by Alexander Bergs and Laurel J. Brinton, 756-776, De Gruyter Mouton, Berlin.

Kytö, Merja, Mats Rydén and Erik Smitterberg, eds. (2006) Nineteenth-Century English: Stability and Change, Cambridge University Press, Cambridge.

Linell, Per (2005) The Written Language Bias in Linguistics, Routledge, London.

Mair, Christian (2006) Twentieth-Century English, Cambridge University Press, Cambridge.

Mair, Christian (2009) "Corpus Linguistics Meets Sociolinguistics," Corpus Linguistics: Refinements and Reassessments, ed. by Antoinette Renouf and Andrew Kehoe, 7-32, Rodopi, Amsterdam.

Massam, Diane (1999) "Thing is Constructions: The Thing is, is What's the Right Analysis?" English Language and Linguistics 3, 335-352.

Partridge, Astley C. (1964) Orthography in Shakespeare and Elizabethan Drama, University of Nebraska Press, Lincoln.

Partridge, Eric (1953) You Have a Point There, Routledge, London.

Omuro, Takeshi (2005) "Eigogaku to Eigokyooiku no Kairi o Umeru Hitotsu no Kanoosei (One Possibility of Filling the Gap between English Linguistics and English Education)," Eigo Seinen 151, 4-6.

Quirk, Randolph and Sidney Greenbaum (1973) A University Grammar of English, Longman, London.

Quirk, Randolph, Sidney Greenbaum, Geoffrey Leech and Jan Svartvik (1985) A Comprehensive Grammar of the English Language, Longman, London.

Roberts, Murat H. (1944) "The Science of Idiom," Publications of the Modern Language Association 59, 291-306. 
Schmid, Hans-Jörg (2000) English Abstract Nouns as Conceptual Shells: From Corpus to Cognition, Mouton de Gruyter, Berlin.

Schneider, Stefan (2007) Reduced Parenthetical Clauses as Mitigators, John Benjamins, Amsterdam.

Shapiro, Michael and Michael C. Haley (2002) "The Reduplicative Copula IS IS," American Speech 77, 305-312.

Shibasaki, Reijirou (under review) "On the Grammaticalization of The Thing is and Related Issues in the History of American English."

Suzuki, Kanji and Chie Miki (2011) Eigo wa Shoorai Koo Kawaru (English Will Change like This), Taishukan, Tokyo.

Thompson, Sandra A. (2002) “'Object Complements' and Conversation: Towards a Realistic Account," Studies in Language 26, 125-164.

Thompson, Sandra A. and Antony Mulac (1991) "A Quantitative Perspective on the Grammaticalization of Epistemic Parentheticals in English," Approaches to Grammaticalization, vol. II, ed. by Elizabeth C. Traugott and Bernd Heine, 313-330, John Benjamins, Amsterdam.

Tieken-Boon van Ostade, Ingrid, ed. (2008) Grammars, Grammarians and Grammar-Writing in Eighteenth-Century England, Mouton de Gruyter, Berlin.

Tieken-Boon van Ostade, Ingrid (2009) An Introduction to Late Modern English, Edinburgh University Press, Edinburgh.

Tieken-Boon van Ostade, Ingrid and van der Wurff, Wim, eds. (2009) Current Issues in Late Modern English, Peter Lang, Berlin.

Traugott, Elizabeth C. (2003) "Constructions in Grammaticalization," The Handbook of Historical Linguistics, ed. by Brian Joseph and Richard Janda, 624-647, Blackwell, Oxford.

Traugott, Elizabeth C. and Graeme Trousdale (2014) Constructionalization and Constructional Change, Oxford University Press, Oxford.

Trousdale, Graeme (2008) "Constructions in Grammaticalization and Lexicalization," Constructional Approaches to English Grammar, ed. by Graeme Trousdale and Nikolas Gisborne, 33-67, Mouton de Gruyter, Berlin.

Tuggy, David (1996) "The Thing is is That People Talk That Way," Cognitive Linguistics in the Redwoods, ed. by Eugene H. Casad, 713-752, Mouton de Gruyter, Berlin.

Van Bogaert, Julie (2011) "I think and Other Complement-Taking Mental Predicates," Linguistics 49, 295-332.

Wierzbicka, Anna (2006) English, Oxford University Press, Oxford.

Wyld, Henry C. (1936) A History of Modern Colloquial English, 3rd ed., Basil Blackwell, Oxford.

\section{Corpora}

A Corpus of Late Modern English Texts (Extended Version) 1710-1920 (CLMETEV), University of Leuven, Belgium (Hendrik De Smet). 
The Corpus of Contemporary American English 1990-2012 (COCA), Brigham Young University, U.S.A. (Mark Davies).

The Corpus of Global Web-Based English (GloWbE), Brigham Young University, U.S.A. (Mark Davies).

The Corpus of Historical American English 1810-2009 (COHA), Brigham Young University, U.S.A. (Mark Davies).

The Helsinki Corpus of English Texts (HC), Early Modern English part 1500-1710, ICAME Collection of English Language Corpora, University of Bergen, Norway.

The Helsinki Corpus of English Texts (HC), Middle English part 1150-1500, ICAME Collection of English Language Corpora, University of Bergen, Norway.

The Modern English Collection 1500-2000s, University of Virginia Electric Text Center.

The Santa Barbara Corpus of Spoken American English (SBCSAE), Department of Linguistics, University of California, Santa Barbara (UCSB).

\section{Dictionaries and Encyclopedia}

Terasawa, Yoshio, ed. (1997) The Kenkyusha Dictionary of English Etymology, Kenkyusha, Tokyo.

The Columbia Encyclopedia (2001), 6th ed., Columbia University Press, New York.

The Oxford English Dictionary (OED) (2009), 2nd ed. on CD-ROM Version 4.0, Oxford University Press, Oxford.

[received September 20, 2013, revised and accepted January 19, 2014]

School of Interdisciplinary Mathematical Sciences

Meiji University

4-21-1 Nakano, Nakano-ku

Tokyo 164-8525

e-mail: reijiro@meiji.ac.jp 